PEMBELAJAR: Jurnal Ilmu Pendidikan, Keguruan, dan Pembelajaran

Volume 5 Nomor 1 April 2021

e-ISSN: 2549-9114 dan p-ISSN: 2549-9203

(Received: Maret-2021; Reviewed: April-2021; Published: April-2021)

DOI: https://doi.org/10.26858/pembelajar.v5i1.15681

\title{
Strategi Penerapan Program Sekolah Ramah Anak Di SD Negeri Kasihan Bantul
}

\author{
Eliana Krisna Wati ${ }^{1}$, Suyatno ${ }^{2}$, Widodo Widodo ${ }^{3}$ \\ Pendidikan Sekolah Guru Dasar, Universitas Ahmad Dahlan, Indonesia \\ Corresponding email: suyatno@pgsd.uad.ac.id
}

\begin{abstract}
Abstrak: Penelitian ini bertujuan untuk mendeskripsikan: 1) Latar belakang penerapan program sekolah ramah anak di SD N Kasihan, 2) Strategi penerapan sekolah ramah anak di SD N Kasihan, dan 3. Dampak penerapan sekolah ramah anak terhadap perkembangan belajar anak. Penelitian ini merupakan penelitian kualitatif dengan jenis studi kasus. Subjek penelitian teridiri dari kepala sekolah, guru, orang tua dan siswa. Penentuan subjek penelitian dilakukan dengan teknik purposive sampling. Teknik pengumpulan data dilakukan dengan menggunakan wawancara, observasi dan dokumentasi. Analisis data menggunakan model Miles \& Huberman, yaitu data reduction, data display, dan penarikan kesimpulan. Hasil penelitian menunjukkan bahwa: 1) Penerapan program sekolah ramah anak didasari karena para siswa di SD N Kasihan sebagian besar pernah mengalami kekerasan baik secara verbal maupun non-verbal. Selain itu, program didukung oleh adanya tekad dan komitmen para guru serta adanya keinginan untuk meningkatkan mutu pendidikan. 2) Implementasi program sekolah ramah anak di Sekolah Dasar Negeri Kasihan dilakukan melalui tahapan sosialisasi, pembinaan soliditas guru, pembiasaan, dan memasukan nilai-nilai sekolah ramah anak dalam proses pembelajaran. 3) Dampak program sekolah ramah anak terlihat dari terbentuknya karakter anak, siswa merasa senang dengan proses pembelajaran di sekolah, dan meningkatnya peran aktif orangtua untuk ikut menerapkan pendidikan ramah anak.
\end{abstract}

Kata Kunci: Sekolah Ramah Anak, Pembelajaran Menyenangkan, SDN Kasihan

Abstract: This study aimed to describe 1) the implementation background of a children-friendly school program in the state primary school of Kasihan, 2) the implementation strategy of children-friendly schools in the state primary school of Kasihan, and 3) the impact of implementing children-friendly school on child learning development. This study was qualitative research using a case study. The research subject consisted of the school principal, teachers, parents, and students. The research subject determination was conducted by using purposive sampling. The technique of data collection was conducted using interviews, observation, and documentation. Data analysis used the Miles \& Huberman model, consisting of data reduction, data display, and drawing conclusions. The research result showed that 1) the implementation of children-friendly schools was based on most of the students in the state primary school of Kasihan who experienced verbal and non-verbal abuse. Besides, this program was supported by teachers' willpower and commitment also the desire to improve education quality. 2) the implementation of a children-friendly school program in the state primary school of Kasihan was conducted through the stages of socializing, fostering teacher solidity, habituating, and inserting the values of the children-friendly school in the learning process. 3) the impact of a childrenfriendly school program was seen from the formation of students' character, the students experienced the happiness in learning proses at school, and the increase of parents' active role was to implement a children-friendly school.

Keywords: Children-friendly school, Fun learning, State primary school of Kasihan.

(C2021-Ini adalah artikel dengan akses terbuka dibawahl icenci CC BY-NC-4.0 (https://creativecommons.org/licenses/by-nc/4.0/) by penulis 


\section{PENDAHULUAN}

Salah satu penghambat peningkatan kualitas pendidikan adalah banyaknya kekerasan di sekolah, baik yang dilakukan oleh sesama siswa maupun guru (Raskauskas et al., 2010; Marcone et al., 2015). Kekerasan di sekolah dapat mengakibatkan siswa merasa stress (Schneider et al., 2012), mengalami penurunan prestasi belajar (Hammig \& Jozkowski, 2013), hingga keluar dari sekolah (Cornell et al., 2013).

Peningkatan kualitas pendidikan hanya dapat dilakukan dengan memperbaiki seluruh komponen pendidikan, diantaranya yaitu dengan menyediakan metode pendidikan yang ramah anak, sehingga anak merasa nyaman berada di sekolah dan dapat belajar dengan optimal. Menurut peraturan menteri negara pemberdayaan perempuan dan perlindungan anak republik Indonesia nomor 05 tahun 2011 tentang kebijakan pemenuhan hak pendidikan anak, sekolah ramah anak adalah sekolah yang didalamnya tidak ada kekerasan terhadap siswa serta terjaminnya keselamatan anak. Sementara itu menurut UNICEF sekolah ramah anak mengcakup berbagai berbagai aspek yang berupaya mewujudkan seluruh kebutuhan anak sebagai pelajar (Wright et al., 2009).

Terdapat tiga prinsip utama pada program sekolah ramah anak, yaitu: 1) Berpusat pada anak, artinya berbagai keputusan dalam pendidikan didasarkan pada kepentingan dan keamanan anak. Anak dilihat sebagai pembelajar yang aktif dan memerlukan lingkungan belajar yang sehat dan aman. 2) Partisipasi demokratis, anak-anak dan dan orangtua berperan dalam mengambil keputusan mengenai bentuk dan substansi pendidikan yang akan dilakukan. 3) Inklusivitas, artinya semua anak memiliki hak untuk mendapat akses pendidikan yang sama, tanpa bergantung pada gender, kondisi fisik serta latar belakang siswa (Wright et al., 2009). Diharapkan, melalui penerapan prinsip-prinsip tersebut akan menjadi suatu langkah progresif untuk meningkatkan kualitas sekolah.

Salah satu sekolah yang menerapkan program sekolah ramah anak adalah Sekolah Dasar Negeri Kasihan. Salah satu misi dari sekolah ini adalah melaksanakan pembelajaran "Ramah Anak". Sekolah ini juga menjadikan program sekolah ramah anak sebagai program unggulan untuk peningkatan mutu pendidikan di Sekolah Dasar Negeri Kasihan. Berdasarkan hasil penelitian sebelumnya ditemukan bahwa peningkatan kualitas lingkungan belajar dapat meningkatkan kehadiran siswa di sekolah, keaktifan dalam pembelajaran, mengurangi angka putus sekolah serta mengurangi perilaku anti sosial dan mendorong peningkatan prestasi anak sehingga memiliki peluang sukses yang lebih banyak (Godfrey et al., 2012). Sekolah ramah anak juga efektif untuk meningkatkan prestasi siswa (Das, 2014).

Berdasarkan latar belakang yang telah diuraikan, implementasi program sekolah ramah anak di SDN Kasihan Bantul menarik untuk diteliti. Penelitian ini bertujuan untuk mengungkap latarbelakang penerapan strategi program sekolah ramah anak serta dampak implementasi program sekolah ramah anak di Sekolah Dasar Negeri Kasihan. Hasil penelitian ini diharapkan dapat dimanfaatkan oleh para pemegan kebijakan baik Dinas pendidikan maupun kepala sekolah, dan guru dalam menerapkan implementasi program sekolah ramah anak.

\section{METODE}

Penelitian ini merupakan penelitian kualitatif dengan pendekatan studi kasus. Data dalam penelitian ini mencakup berbagai deskripsi mendetail mengenai permasalahan yang diteliti, yang kemudian dijelaskan secara deskriptif untuk mengetahui gambaran strategi pengembangan mutu melalui penerapan program sekolah ramah anak.

\subsection{Setting dan Waktu Penelitian}

Penelitian ini dilaksanakan di Sekolah Dasar Negeri Kasihan, Bantul, Yogyakarta. Sekolah Dasar Negeri Kasihan merupakan sekolah dasar negeri yang telah menerapkan program sekolah ramah anak. Adapun pelaksanaan penelitian ini dilakukan pada semester genap tahun ajaran 2018/2019.

\subsection{Subjek dan Objek Penelitian}

Subjek pada penelitian ini yaitu sepuluh orang narasumber yang terdiri dari satu orang kepala sekolah Sekolah Dasar Negeri Kasihan, enam orang guru Sekolah Dasar Negeri Kasihan, dua orang siswa Sekolah Dasar Negeri Kasihan dan satu orang wali siswa Sekolah Dasar Negeri Kasihan. Pemilihan subjek didasarkan pada tujuan penelitian sehingga subjek dipilih secara purposive. Objek dalam penelitian ini yaitu strategi pengembangan mutu berbasis keunggulan sekolah di Sekolah Dasar Negeri Kasihan. 


\subsection{Teknik dan Instrumen Pengumpulan Data}

Pengumpulan data pada penelitian ini menggunakan teknik observasi, wawancara dan dokumentasi. Hal ini bertujuan agar data yang diperoleh cukup representatif untuk menggambarkan fenomena di lokasi penelitian. Instrumen pengumpulan data menggunakan guideline wawancara, observasi, dan dokumentasi yang disusun oleh peneliti. Sebelum digunakan, guideline penelitian telah dikonsultasikan kepada dosen ahli dan direvisi sesuai dengan saran-saran yang diberikan.

\subsection{Keabsahan Data}

Pengujian keabsahan data yang terkumpul dilakukan dengan triangulasi yaitu mencocokan hasil wawancara antar subjek serta mencocokan hasi wawancara dengan dokumen pendukung diantaranya perangkat pembelajaran, media pembelajaran, program kerja guru bimbingan dan konseling, data kepegawaian, tata tertib di sekolah, serta hasil dokumentasi kegiatan.

\subsection{Teknik Analisis Data}

Analisis data pada penelitian ini menggunakan analisis interactive model yang dikembangkan oleh Miles dan Huberman. Miles dan Huberman (1994) membagi proses analisis data kedalam beberapa tahap yaitu, pengumpulan data (data collection), reduksi data (data reduction), penyajian data (data display), dan penarikan kesimpulan atau verifikasi (conclutions).

\section{HASIL PENELITIAN}

Penyajian data penelitian ini didasarkan pada kepentingan untuk menjawab rumusan masalah penelitian yang telah diajukan. Data dikelompokkan berdasarkan kesesuaiannya dengan tujuan menjawab rumusan masalah dan masing-masing kategori tersebut dipilah menjadi tema-tema yang sesuai.

\subsection{Latar Belakang Penerapan Program Sekolah Ramah Anak}

Berdasarkan hasil wawancara dengan kepala sekolah dan guru di SD Kasihan Bantul terungkap bahwa latar belakang program Sekolah Ramah Anak di SD Kasihan adalah melihat fenomena kekerasaan yang terjadi di sekolah melalui berbagai pemberitaan media membuat orang tua khawatir. Sehingga pemerintah melakukan berbagai upaya untuk mengurangi angka kekerasan yang terjadi dengan berbagai macam upaya. Salah satunya adalah menghimbau seluruh satuan pendidikan untuk menjadikan sekolahnya ramah bagi siswa. Keramahan pada sekolah pada sekolah bertujuan untuk beberapa hal diantaranya 1. Melindungi hak anak. 2. Mencegah adanya kekerasan yang dilakukan baik teman maupun guru serta karyawan. 3. Mencegah anak sakit karena makanan yang ada di sekolah. 4. Mencegah anak sakit karena sarana dan prasarana yang ada di sekolah. 5. Melindungi anak dari serangan NARKOBA dan rokok.6. Menciptakan hubungan hangat anar warga sekolah. 7. Memudahkan pemantauan anak di sekolah.8 Menciptakan lingkungan yang bersih dan hijau. 9. Mengembangkan minat bakat anak. 10. Menjadikan anak betah di lingkungan sekolah. 11. Peserta didik terbiasa dengan pembiasaan baik (Dokumentasi, 4 Februari 2019).

Tujuan di atas tentu tidak mudah dan memerlukan waktu yang cukup lama serta kerja sama dan komitmen berbagai pihak. Akan tetapi jika hal ini ditangani dengan serius maka sekolah akan mencetak generasi anti kekerasan. Seperti yang dikatakan KS berdasarkan wawancara bahwa:

Kami menyadari bahwa untuk mewujudkkan tujuan Sekolah ramah anak membutuhkan waktu yang lama. Akan tetapi kami merasa bahwa sesulit dan selama apapun sebuah program jika ditekuni dan dijalani bersama pasti akan terwujud. Tekad itulah yang membuat kami mantap menjalankan program ramah anak. Komitmen bersama guru" Wawancara dengan KS, tanggal 4 Februari 2019).

Dalam hal penyelenggaraan pendidikan harus dilaksanakan dengan dasar keramahan yang telah ditentukan. Selain itu guru diharapkan mampu menfasilitasi peserta didik dalam memenuhi hakhaknya serta melindungi mereka dari bentukbentuk kekerasan. Sebagai pendidik guru juga perlu berperan aktif dalam memberi teladan terhadap peserta didik. Teladan tersebut seperti menyapa dengan ramah, memberi hak yang sama kepada semua peserta didik, mengajak hidup sehat, dan memberikan contoh pembiasaan positif. Seperti yang diungkapkan KS sebagai berikut:

Pembiasaan yang menerapkan ramah anak senyum, salam, sapa yang dilakukan di sekolah setiap pagi para guru piket berjabat tanggan menanti peserta didik saat masuk 
sekolah" (Wawancara dengan KS, tanggal 4 Februari 2019).

Berdasarkan hasil observasi KS tanggal 30 Januari 2019 bahwa SD Kasihan dalam program SRA penting membangun komitmen. Dalam kerjasama dibutuhkan komitmen pada diri individu. Begitu pula dalam pelaksanaan program di sebuah instansi atau perusahaan semua pihak yang terlibat harus mempunyai komitmen maka tujuan dari program tersebut susah untuk diwujudkan. Seperti yang diungkapkan guru mapel pada observasi tanggal 30 Januari 2019 bahwa:

Menumbuhkan rasa memiliki sekolah pada setiap pihak baik, sekolah, orang tua, atau masyarakat. Menumbuhkan rasa semangat bekerja pada masing-masing guru, memperbaiki manajemen hidup" (Obsevasi dengan MNJ tanggal 30 januari 2019).

Dengan komitmen yang kuat dari tiga belah pihak maka program sekolah ramah anak akan terwujud dengan mudah. Kepala sekolah dan Guru memahami betul bahwa peserta didik kurang perhatian dari keluarga. Sehingga SD Kasihan mengatasi permasalahan tersebut dengan menjadikan sekolah sebagai keluarga peserta didik. Artinya dalam proses belajar guru harus menyertakan kehangatan layaknya keluarga. Sehingga peserta didik merasakan kebahagiaan, perhatian kasih ayang orang tua di sekolah di sekolah yang tidak ditemkan di rumah. Maka dari itu Materi sosialisasi tentang ramah anak tersebut disampaikan kepada orang tua peserta didik dalam sosialisasi seperti telah diungkapkan oleh Guru kelas atas IMF SD Kasihan yakni bahwa:

Mendidik peserta didik dengan pendidikan dari kebudayaan sendiri. Pengajaran ramah anak menghargai orang lain, kerja sama/gotong royong, menjalankan ibadah/religius, upacara bendera/nasionalis, akan menanamkan pendidikan karakter. (Observasi dengan IMF, tanggal 1 Februari 2019).

Dalam menjadikan sekolah keluarga, tentu memerlukan kesabaran yang tinggi. Karena banyak peserta didik yang ketika di dekati masih mengamuk, marah-marah dan lain sebagainya. Selain itu butuh waktu yang lama untuk membuat hati mereka percaya bahwa masih ada yang peduli dan memperhatikan.

Pendidikan diawali dari keluarga. Keluarga adalah tempat pertama bagi pembentukan dan pendidikan anak. Orang tua dan rumah adalah sekolah pertama yang dikenal oleh anak, karena peran orang tua disini sangat penting. Melalui orang tualah anak akan belajar mengenal nilainilai dan norma sebelum anak memasuki jenjang pendidikan sekolah dasar. Orang tua harus memiliki bekal mengenai berbagai macam informasi tentang pendidikan anak. Seperti yang diungkapkan wali murid LDY sebagai berikut:

Dengan 5 karakter yaitu Religius, nasionalis, mandiri, gotong royong, integritas. Karena selama anak saya sekolah di SD kasihan karakter anak saya lebih baik dari sebelumnya. Apalagi SD Kasihan menggunakan program sekolah unggulan ramah anak jadi disitu anak saya sudah terbiasa berkarakter baik dan sopan. (Wawancara LDY tanggal 4 Februari 2019).

Orang tua harus memberikan teladan yang baik bagi anak-anaknya, karena anak usia dini adalah peniru. Anak akan belajardalam tahap imitasi yaitu meniru apa yang dilihat dan didengar anak akan ditiru oleh anak. Jadi orang tua harus berhati-hati dalam perilaku maupun perkataan.

SDN Kasihan memiliki visi untuk mewujudkan insan yang bertaqwa, cerdas dan berkarakter dengan indikator 1) Mampu mengamalkan ajaran agama sesuai yang dianutnya, 2) Mampu meraih prestasi akademik yang optimal, dan 3) Mampu melaksanakan pembelajaran "Ramah Anak". Untuk mewujudkan visi tersebut SDN Kasihan mempunyai program unggulan yaitu program sekolah ramah anak, program ini juga di proyeksikan sebagai salah satu upaya peningkatan mutu sekolah. implementasi program SRA didukung oleh beberapa komponen yaitu:

\subsubsection{Tekad dan komitmen para guru}

Program sekolah ramah anak di Sekolah Dasar Negeri Kasihan dilatarbelakangi oleh adanya himbauan pemerintah untuk menjadikan seluruh sekolah sebagai sekolah ramah anak. Program tersebut tersebut dibarengi oleh adanya tekad dan komitmen dari para guru untuk mewujudkan Sekolah Dasar Negeri Kasihan sebagai sekolah ramah anak, hal ini sebagaimana hasil wawancara dengan subjek berikut:

"Kami menyadari bahwa untuk mewujudkkan sekolah ramah anak membutuhkan waktu yang lama. Akan tetapi kami merasa bahwa sesulit dan selama apapun sebuah program jika ditekuni dan dijalani bersama pasti akan terwujud. Tekad itulah yang membuat kami 
mantap menjalankan program ramah anak. Komitmen bersama guru” (KS, Guru Sekolah Dasar Negeri Kasihan).

Tujuan diatas tentu tidak mudah dan memerlukan waktu yang cukup lama serta kerjasama sama dan komitmen berbagai pihak. Akan tetapi jika hal ini ditangani dengan serius maka sekolah akan mencetak generasi anti kekerasan. Dengan melaksanakan sekolah ramah anak. Untuk mewujudkan keramahan di sekolah baik guru, orang tua, dan masyarakat perlu mempelajari maksud dan tujuan dari Sekolah Ramah anak. Sehingga dalam pelaksanaanya semua memahami tugas dan kewajiban masingmasing.

\subsubsection{Adanya keinginan untuk meningkatkan mutu pendidikan}

Sekolah ramah anak menjadi program unggulan yang diharapkan dapat menjadi sarana untuk peningkatan mutu pendidikan di Sekolah Dasar Negeri Kasihan, hal ini sebagaimana hasil wawancara dengan subjek berikut:

"Sekolah kami menetapkan kebijakan penguatan karakter melalui penerapan sekolah ramah anak untuk menjamin mutu pendidikan nasional dalam rangka mencerdaskan kehidupan bangsa, membentuk karakter dan peradaban bangsa yang bermartabat” (KS, Guru Sekolah Dasar Negeri Kasihan).

Dengan memasukan Pendidikan karakter disetiap pembelajaran meliputi Religius, mandiri, nasionalis, gotong royong, integritas. Pendidikan karakter dapat mendorong peserta didik untuk beradaptasi di setiap lingkungan.

\subsection{Implementasi Program Sekolah Ramah Anak di Sekolah Dasar Negeri Kasihan}

Implementasi program sekolah ramah anak melalui berbagai tahapan pelaksanaan, yaitu sosialisasi, membina soliditas guru, pembiasaan, Memasukan nilai-nilai sekolah ramah anak dalam proses pembelajaran

\subsubsection{Sosialisasi}

Sosialisasi merupakan tahapan untuk menginformasikan program yang akan dilakukan. Program sekolah ramah anak di Sekolah Dasar Negeri Kasihan diawali dengan sosialisasi terutama bagi guru, staf dan orangtua siswa, hal ini sebagaimana cuplikan wawancara berikut:

"Kami sebagai guru di Sekolah Dasar Kasihan Bantul ini setiap tahun awal pelajaran selalu diberikan sosialisasi tentang ramah anak sesuai penguatan karakter supaya kami para guru dapat selalu menerapkan sekolah ramah anak tersebut terhadap peserta didik kami" (MNJ, Guru Sekolah Dasar Negeri Kasihan).

Menyampaikan sosialisasi 1 bulan sekali di kegiatan parenting gunanya untuk memberikan pengetahuan kepada orantgtua tentang sekolah ramah anak, memberi tahu peran orangtua dalam penerapan program tersebut, agar memudahkan untuk diajak bekerjasama. Untuk menyampaikan perkembangan sekolah berkeunggulan tentang ramah anak maka setiap 2 bulan sekali diadakan sosialisasi ramah anak kepada staf guru karyawan dan orang tua siswa.

\subsubsection{Membina Soliditas Guru}

Pelaksanaan progam sekolah ramah anak memerlukan komitmen dan kerjasama dari semua guru Sekolah Dasar Negeri Kasihan. Oleh karena itu, sekolah berupaya membangun soliditas guru dengan mengadakan breefing setiap pekan, hal ini sebagaimana hasil wawancara berikut:

"Keakraban yang dilakukan guru menjadi realita yang dilaksanakan dipagi hari seperti breafing 15 menit setiap selesai upacara hari senin. Tujuanya agar semua informasi yang di dapatkan guru dapat mengena kepeserta didik. Dalam breafing 15 menit tersebut ditekankan bahwa dalam pembelajaran jangan sampai ada kekerasan yang ada saling menghargai dengan ramah." (KS, Guru Sekolah Dasar Negeri Kasihan).

Pembinaan guru bertujuan agar guru memahami pentingnya sekolah ramah anak dan dapat mengimplementasikannya dengan baik. Memberikan pemahaman kepada guru agar selalu memasukkan konsep karakter ramah anak dalam pembelajaran dengan menyampaikan pentingnya konsep karakter ramah anak bagi perkembangan kepribadian. Menyampaikan ke Guru bahwa pembelajaran kunci utama perkembangan komptensi siswa secara maksimal.

\subsubsection{Pembiasaan}

Program sekolah ramah anak diwujudkan melalui berbagai program pembiasaan (habituasi). Pembiasaan ini dilakukan sejak siswa mulai memasuki sekolah di pagi hari, hal ini sebagaimana hasil wawancara berikut:

"Pembiasaan penerapan program ramah anak dimulai dari senyum, salam, sapa yang dilakukan di sekolah setiap pagi para guru 
piket berjabat tanggan menanti peserta didik saat masuk sekolah" (KS, guru Sekolah Dasar Negeri Kasihan).

Pengajaran ramah anak dilakukan dengan menghargai orang lain, kerja sama/gotong royong, menjalankan ibadah/religius, upacara bendera/ nasionalis, serta menanamkan pendidikan karakter.

"Penanam karakter dibiasakan di SD kasihan dengan ramah dan kasih sayang... Setiap pagi dimulai dengan tepuk PPK, menyanyikan lagu wajib, berdoa sebelum pelajaran" (NSK, Guru Sekolah Dasar Negeri Kasihan).

Mengajar dengan sabar dan ramah, tidak ada hukuman untuk peserta didik yang melanggar peraturan, adanya pengarahan yang mendidik. Setiap pagi melaksanakan apel pagi, tujuannya untuk menerapkan karakter. Salah satu upaya pembiasaan baik dalam kegiatan di sekolah adalah dengan memberkan pengaharan dan memberikan contoh atau teladan yang baik. Hal ini sebagaimana hasil wawancara berikut:

"Menjadi contoh teladan dalam perilaku sehari-hari. Dicontohkan missal tutur kata pada peserta didik sopan santun. Keteladanan diri dan warga sekolah menghargai agama lain, kerjasama/gotong royong, menjalankan ibadah/religius. Tertib dalam berprilaku dan tindakan, tertib dalam administrasi” (KS, guru Sekolah Dasar Negeri Kasihan).

Guru mengarahkan siswa dalam pembiasaan bertutur kata, tingkah laku yang mengarah pada karakter yang baik, guru melatih membiasakan untuk disiplin supaya kedisiplinan itu sendiri timbul dari diri siswa sendiri. Jika anak melakukan kesalahan langsung diberikan teguran, dibetulkan, diperingatkan dan arahan secara sepontan dengan memperhatikan tindakan yang membimbing dan mendidik.

"Guru memberikan keteladanan dalam kehadiran, berpakaian, berpenampilan yang menarik, kedisiplinan, kesopanan dan tutur kata yang baik" (IMF, guru Sekolah Dasar Negeri Kasihan).

Guru selalu mendidik dengan memberikan teladan langsung dalam kegiatan setiap hari, saling menghargai, disiplin saat berada di dalam maupun diluar sekolah dengan menerapkan metode ramah anak. Guru ramah dengan senyum, salam, sapa, sopan santun guru mencontohkan perilaku yang baik.

\subsubsection{Memasukan nilai-nilai sekolah ramah anak dalam proses pembelajaran}

Nilai-nilai sekolah ramah anak dimasukan dalam pembelajaran terutama pada bagian pendidikan karakter bagi anak. Hal ini sebagaimana hasil wawancara berikut:

"Untuk memberikan pelayanan yang terbaik kepada peserta didik kami di lingkungan Sekolah Dasar Negeri Kasihan yang bernafaskan sekolah ramah anak maka kami selalu menggunakan program ramah anak dalam pendidikan, sehingga sebagai ciri khas pendidikan di lingkungan Sekolah Dasar Negeri Kasihan Bantul adalah dengan program ramah anak" (MNJ, guru Sekolah Dasar Negeri Kasihan).

Guru menciptakan proses pembelajaran yang menarik dan kontekstual yaitu disesuaikan dengan karakteristik dan perkembangan jaman, guru memberikan keteladanan dalam kehadiran, berpakaian, berpenampilan yang menarik, kedisiplinan, kesopanan dan tutur kata yang baik. Guru juga memberikan materi pembelajaran yang terintegrasi dengan budaya Jawa karena apabila di kaji mendalam budaya Jawa sarat akan nilai-nilai budi pekerti dan disesuaikan dengan perkembangan zaman.

"Dengan program ramah anak yang tujuannya untuk melindungi hak anak, mencegah adanya kekerasan, mengembangkan minat bakat anak, menjadikan peserta didik dalam pembiasaan. Memerlukan waktu yang cukup lama maka dari itu di setiap pembelajaran selalu memasukan konsep ramah anak. (MNJ, guru Sekolah Dasar Negeri Kasihan).

Memberikan pembelajaran yang menarik dengan model dan metode yang menyesuaikan kondisi siswa. Sehingga siswa mengikuti pembelajaran dengan senang. Proses pembelajaran di Sekolah Dasar Negeri Kasihan memasukan nilai-nilai ramah anak dengan melakukan berbagai kegiatan sebelum dan sesudah pembelajaran. Hal ini sebagaimana kutipan wawancara berikut:

"Pembelajaran diawali Tepuk PPK (Religius, mandiri, nasionalis, gotong royong, integritas), lalu berdoa sebelum dan sesudah pelajaran. Anak-anak diajarkan religius, mandiri, nasionalis, gotong, royong, integritas di lingkungan sekolah dan di dalam pembelajaran" (IVJ, guru Sekolah Dasar Negeri Kasihan).

Religius, nasionalis, mandiri, gotong royong, intergritas dalam proses pembelajaran religius berdoa sebelum dan sesudah proses pembelajaran. Nasional menyanyikan lagu Indonesia Raya sebelum proses pembelajaran dan lagu wajib nasional sesudah pembelajaran, mandiri mengerjakan tugas secara mandiri tanpa 
bantuan teman, gotong royong dapat bekerja sama dalam kelompok, integritas bersikap jujur dalam segala hal misalnya memngerjakan penilaian harian dengan jujur tanpa menyontek".

\subsubsection{Membangun kerjasama dengan berbagai pihak}

Sekolah ramah anak dapat diwujudkan apabila ada perasaan saling memiliki sehingga semua pihak bersedia untuk berkontribusi dan mendukung program sekolah ramah anak. Hal ini sebagaimana hasil wawancara berikut:

"Tujuan dari Sekolah Dasar Negeri Kasihan yaitu dengan melaksanakan Sekolah ramah anak. Untuk mewujudkan keramahan di sekolah baik guru, orang tua, dan masyarakat perlu mempelajari maksud dan tujuan dari sekolah ramah anak. Sehingga dalam pelaksanaannya semua memahami tugas dan kewajiban masing-masing agar tidak terjadi kesalah pahaman" (KS, guru Sekolah Dasar Negeri Kasihan).

Program sekolah ramah anak memerlukan dukungan dari berbagai pihak. Oleh karena itu sekolah berupaya untuk bekerjasama terutama dengan orangtua. Hal ini sebagaimana hasil wawancara berikut:

"Kerja sama antara guru dan wali murid sangat penting untuk penguatan karakter di sekolah maupun di rumah. Dengan adanya kerja sama saya sebagai wali murid bisa memantau anak saya seiap hari dengan komunikasi guru SD Kasihan yang ramah." (LDY, orangtua siswa Sekolah Dasar Negeri Kasihan).

Salah satu upaya agar orangtua memahami pentingnya sekolah ramah anak adalah dengan mengadakan kegiatan parenting. Hal ini sebagaimana kutipan wawancara berikut:

"Saya selalu mengikuti kegiatan parenting yang diadakan di sekolah, didalam parenting selain saya tambah pengetahuan di situ juga disampaikan tentang perkembangan siswa, selalu ada evaluasi dan perbaikan." (LDY, orangtua siswa Sekolah Dasar Negeri Kasihan).

Orangtua sebagai pihak yang secara langsung berhubungan dengan perkembangan anak disediakan wadah aspirasi dan komunikasi melalui sebuah paguyuban orangtua siswa. Hal ini sebagaimana hasil wawancara berikut:

"Orang tua dan masyarakat mendukung program sekolah, Menjalin persaudaraan antar orang tua satu dengan yang lain sehingga terbentuk persatuan yang kuat dalam berperan aktif memajukan sekolah. Dalam hal ini paguyuban juga dapat menyalurkan aspirasi atas keputusan sekolah yang memberatkan orang tua misal masalah penarikan dana untuk sekolah" (IMF, guru Sekolah Dasar Negeri Kasihan).

Tujuan dari kerja sama tersebut adalah untuk memajukan kualitas belajar dan pertumbuhan anak. Selain itu juga mengkokohkan tujuan dan memajukan kualiatas penghidupan masyarakat. Dalam pemberian edukasi Tri Pusat Pendidikan sekolah harus melalui beberapa prinsip diantaranya keterpaduan, terus menerus, daan menyeluruh.

\subsection{Dampak Program Sekolah Ramah Anak terhadap Perkembangan Belajar Siswa}

Program sekolah ramah anak terbukti dapat meningkatkan kualitas peserta didik. Hal tersebut akan mendukung pada peningkatan mutu pendidikan di Sekolah Dasar Negeri Kasihan secara umum. Efektifitas program sekolah ramah anak di Sekolah Dasar Negeri Kasihan terlihat dari:

\subsubsection{Terbentuknya karakter anak}

Penerapan program sekolah ramah anak dapat memberikan kemajuan berupa terciptanya karakter anak yang baik dan sopan. Hal ini sebagaimana kutipan wawancara berikut:

"Selama anak saya sekolah di Sekolah Dasar Negeri Kasihan karakter anak saya lebih baik dari sebelumnya. Apalagi Sekolah Dasar Negeri Kasihan menggunakan program sekolah unggulan ramah anak jadi disitu anak saya sudah terbiasa berkarakter baik dan sopan" (LDY, orangtua siswa Sekolah Dasar Negeri Kasihan).

Dengan menanamkan karakter dari usia dini, pesrta didik SD kasihan sudah mulai mempunyai kesadaran diri untuk melakukan segala sesuatu dengan baik. Program sekolah ramah anak efektif untuk meningkatkan kecakapan hidup anak. Hal ini sebagaimana kutipan wawancara berikut:

"Dengan program sekolah Ramah Anak kecakapan hidup peserta didik sudah mulai terlihat dari berbagai bidang seperti sudah mandiri, mempunyai kesadaran diri, memanfaatkan teknologi, mengumpulkan tugas dengan tepat waktu, bekerjasama dengan orang lain" (KS, guru Sekolah Dasar Negeri Kasihan).

Kenyamanan yang dirasakan siswa ketika berada di sekolah membuat proses belajar dan bersosialisasi siswa di sekolah dapat berjalan dengan baik. Hal ini sebagaimana hasil wawancara berikut:

"Kegiatan rutin yang dilaksanakan peserta didik sesuai jadwal membaca dan meminjam 
buku di perpustakaan dengan penuh tanggungjawab" (WNP, guru Sekolah Dasar Negeri Kasihan).

Kegiatan rutin meliputi piket kelas peserta didik melaksanakan dengan bekerja sama. Dan selalu melaksanakan kegiatan jumat bersih membersihkan lingkungan sekolah bersamasama.

\subsubsection{Siswa merasa senang dengan proses pembelajaran di sekolah}

Pembelajaran ramah anak yang diterapkan membuat anak senang berada di sekolah. Hal ini sebagaimana kutipan wawancara berikut:

"Saya merasa senang sekolah disini karena apabila saya salah tidak dimarahi akan tetapi saya dibimbing dan diarahkan supaya tidak melakukan kesalahan lagi." (RAP, siswa Sekolah Dasar Negeri Kasihan).

Sekolah memberikan fasilitas yang dibutuhkan peserta didik, fasilitas tempat yang sangat nyaman dan bersih sehingga peserta didik belajar dengan nyaman. Guru mengajar dengan ramah dan sabar sehingga peserta didik mengikuti pelajaran dengan senang.

\subsubsection{Adanya peran aktif dari orangtua untuk ikut menerapkan pendidikan ramah anak}

Kerjasama yang dijalin baik dengan orangtua membentuk sinergisitas pendidikan di sekolah dan di rumah. Hal ini sebagaimana kutipan wawancara berikut:

"Yang saya terapkan sama dengan bapak/ibu contohkan di sekolah. Bersikap baik dalam tutur kata, jujur, ramah. Karena saya setiap hari melihat bapak/ibu guru memberi teladan jadi saya mempunyai pembiasaan yang saya terapkan" (MN, orangtua siswa Sekolah Dasar Negeri Kasihan).

Orangtua bersedia untuk ikut mensukseskan program sekolah ramaha anak dengan ikut menerapkan berbagai sikap dan keteladanan yang diajarkan oleh guru di sekolah di rumah masingmasing.

\section{PEMBAHASAN}

Berdasarkan analisis data yang dilakukan, terdapat temuan penting dalam penelitian ini yaitu: pertama, penerapan program SRA di SDN Kasihan dilatar belakangi oleh adanya kesadaran akan pentingnya program pendidikan yang ramah anak mengingat para siswa memiliki latar belakang mengalami kekerasan baik fisik maupun non-fisik. Latar belakang tersebut dikuatkan dengan adanya tekada para guru dan adanya keinginan untuk meningkatkan mutu pendidikan. Kedua, strategi penerapan SRA di SDN Kasihan bantul dilaksanakan dengan tahapan sosialisasi, membina soliditas guru, pembiasaan, memasukkan nilai-nilai sekolah ramah anak dalam proses pembelajaran, dan membangun kerjasama dengan berbagai pihak. Ketiga, program SRA telah berdampak terhadap meningkatnya karakter siswa, siswa merasa senang dengan proses pembelajaran di sekolah, dan meningkatkan peran aktif dari orangtua untuk ikut menerapkan pendidikan ramah anak.

Temuan penelitian pertama mendukung temuan-temuan sebelumnya yang menyebutkan bahwa komitmen guru adalah salah satu hal yang penting untuk menentukan keberjalanan proses pembelajaran (Sharma, 2015). Komitmen terlihat dari adanya ikatan antara seseorang dengan objek yang menjadi tujuan komitmennya, pada guru komitmen mancakup komitmen terhadap profesi dan komitmen terhadap organisasi (Collie et al., 2011). Guru yang memililiki komitmen yang tinggi dapat mengajar dengan lebih efektif (Sharma, 2015), work engagement yang tinggi (Cao et al., 2019), tingginya knowledge sharing dan performance (Eliyana et al., 2019; Imamoglu et al., 2019), memiliki organizational citizenship behavior yang tinggi (Aguiar-Quintana et al., 2020) dan dapat menurunkan tingkat turnover (Scales \& Quincy Brown, 2020; Zhou et al., 2020). Komitmen guru yang tinggi membuat mereka memiliki ikatan yang kuat dengan siswa. Hal terebut membuat guru berusaha untuk dapat mengajar dengan lebih efektif, bersedia terlibat dengan berbagai program yang dapat menunjang pembelajaran serta menunjukkan performa kerja yang baik. Guru yang berkomitmen juga bersedia untuk melakukan kerjasama dengan guru lainnya melalui kesediaan untuk sharing pengetahuan antar guru, bersedia bekerja diluar jobdesknya serta memiliki loyalitas yang tinggi terhadap pekerjaannya. Selain itu, adanya keinginan untuk meningkatkan mutu pendidikan juga turut mendukung kesuksesan program SRA. Peningkatan kualitas pendidikan menjadi isu penting dalam upaya pengembangan pendidikan, sehingga diperlukan perencanaan programprogram untuk mewujudkan pengembangan pendidikan tersebut (Zhang et al., 2018). Salah satu upaya peningtakan mutu pendidikan adalah melalui program sekolah ramah anak. Program sekolah ramah anak merupakan suatu upaya peningkatan kualitas pendidikan dengan 
memperhatikan pengembangan bakat dan kepribadian anak (Kegode \& Kadenyi, 2016) Sekolah Dasar Negeri Kasihan menjadikan program sekolah ramah anak sebagai salah satu upaya peningkatan kualitas pendidikan di sekolah tersebut. Sekolah ramah anak dianggap sebagai program yang dapat mewujudkan siswa yang berkarakter dan bermartabat.

Kedua, implementasi Program Sekolah Ramah Anak di Sekolah Dasar Negeri Kasihan diawali oleh kegiatan sosialisasi. Sosialisasi menjadi tahap awal dalam penerapan program sekolah ramah anak. Sosialisasi adalah proses memberikan pengetahuan baru agar setiap orang dalam organisasi mengetahui peran dan tugasnya (Kowtha, 2018). Sosialisasi yang baik membuat guru mengetahui perannya dengan jelas, dapat melakukan integrasi pekerjaan serta dapat mengurangi konflik karena ketidakjelasan peran (Bauer et al., 2007). Hasil penelitian (Ang et al., 2015) menunjukkan bahwa sosialisasi tidak hanya memudahkan karyawan mengetahui peran sosialnya, tetapi juga dapat membantu karyawan melakukan penyesuaian diri dengan tugas-tugas mereka. Sosialiasi yang dilakukan di Sekolah Dasar Negeri Kasihan membuat guru, staf dan orangtua dapat memahami peranannya dalam penerapan sekolah ramah anak. Kegiatan sosialiasasi yang dilakukan secara berkala membuat guru dan orangtua lebih mudah memahami tugasnya. Kedua, Membina soliditas guru. Pelaksanaan progam sekolah ramah anak memerlukan solidaritas guru yang digambarkan melalui komitmen dan kerjasama dari semua guru. Solidaritas mengacu pada suatu situasi saat kesejahteraan seseorang atau kelompok berkaitan dengan kesejahteran yang lain (Koster \& de Beer, 2009). Solidaritas yang baik membuat karyawan berupaya mentaati aturan dan menurunkan penyimpangan (Itzkovich \& Heilbrunn, 2016), sehingga guru akan bekerja sesuai tugasnya dan hal ini dapat meningkatkan prestasi siswa (Hargreaves \& O'Connor, 2018), (Schleifer \& Rinehart, 2020). Guru yang memiliki soliditas tinggi akan memahami bahwa setiap tugas yang dilakukan akan mempengaruhi kinerja dari sekolah secara keseluruhan, oleh karena itu guru akan merasa bertanggungjawab untuk dapat bekerja secara maksimal. Ketiga, pembiasaan. Pembiasaan adalah penurunan respons perilaku yang dihasilkan dari stimulasi berulang, proses ini dapat menimbulkan berbagai respons sederhana sesuai dengan apa yang di programkan (Rankin et al., 2009). Pembiasaan dilakukan dengan pemberian stimulus tertentu secara berulang (Hall \& Rodríguez, 2017). Dalam penerapan program sekolah ramah anak, proses pembiasaan dilakukan dengan pemberian contoh perilaku sopan santun yaitu senyum, salam dan sapa. Selain itu, pembiasaan juga dengan berupa pemberian contoh, terutama dalam hal cara berkomunikasi, berpenampilan serta berperilaku. Keempat, memasukan nilai-nilai sekolah ramah anak dalam proses pembelajaran. Pembelajaran di Sekolah Dasar Negeri Kasihan menerapkan berbagai metode seperti inquiri learning, project based learning, problem based learning, serta contextual learning. Pembelajaran dengan metode yang berfariasi membuat anak lebih mudah untuk menerima materi yang diajarkan. Misalnya pada metode inquiry learning siswa dapat secara aktif terlibat dan mendapatkan pengalaman baru dengan melakukan kegiatan yang memingkinkan siswa menemukan konsep dan prinsip secara mandiri (Slavin, 1994). Kemudian contextual learning dapat melatih berpikir kritis dan problem solving dengan menghubungkan materi pembelajaran dengan konteks keterampilan yang dapat digunakan siswa dalam kehidupannya (Surya et al., 2017). Penggunaan berbagai metode tersebut di sesuaikan dengan materi yang di ajarkan. Namun, selain memperhatikan kesesuaian metode pembelajaran guru juga berupaya untuk memasukan aspek-aspek pembelajaran ramah anak pada setiap proses pembelajaran.

Ketiga, implementasi program SRA telah berdampak pada pengembangan karakter anak, siswa merasa senang dengan proses pembelajaran di sekolah, dan meningkatkan partisipasi aktif orang tua di sekolah. Penerapan program sekolah ramah anak dapat memberikan kemajuan berupa terciptanya karakter anak yang baik dan sopan, serta memiliki kemampuan bersosialisasi dan kecakapan hidup yang baik. Penelitian ini relevan dengan penelitian sebelumnya yang menyebutkan bahwa pendidikan ramah anak efektif untuk meningkatakan kreativitas siswa (Lian et al., 2018). Sekolah ramah anak juga dapat menjadi alternatif metode untuk mengasah keterampilan, kemandirian, kreativitas serta pengembangan kemampuan kecakapan hidup (Kegode \& Kadenyi, 2016). Siswa merasa senang dengan proses pembelajaran di sekolah. Pembelajaran ramah anak yang diterapkan membuat anak senang berada di sekolah. Temuan ini relevan dengan hasil penelitian sebelumnya yang meyatakan bahwa siswa yang mendapat pengalaman perlakuan baik di sekolah akan lebih 
bahagia (Stiglbauer et al., 2013). Sekolah ramah anak membuat siswa merasa nyaman dan senang ebrada di sekolah hal ini berimplikasi pada peningkatan keberhasilan akademik serta kemampuan bersosialisasi siswa (Afnibar, 2017). Adanya peran aktif dari orangtua untuk ikut menerapkan pendidikan ramah anak. Penerapan program sekolah ramah anak berhasil membuat orangtua lebih bersedia untuk terlibat dalam pendidikan anak. Kerjasama ini menciptakan sinergisitas pendidikan di sekolah dan di rumah sehingga anak-anak akan lebih cepat dalam memahami dan mernerapkan pengetahuan dan sikap yang dipelajar.

\section{KESIMPULAN}

Berdasarkan hasil penelitian, diketahui bahwa latarbelakang penerapan strategi program sekolah ramah anak di Sekolah Dasar Negeri Kasihan adalah adanya Tekad dan komitmen para guru serta adanya keinginan untuk meningkatkan mutu pendidikan. Kemudian, implementasi program sekolah ramah anak di Sekolah Dasar Negeri Kasihan dilakukan dengan adanya sosialisasi, pembinaan soliditas guru, pembiasaan, serta memasukan nilai-nilai sekolah ramah anak dalam proses pembelajaran. Adapun dampak program sekolah ramah anak di Sekolah Dasar Negeri Kasihan terlihat dari terbentuknya karakter anak, siswa merasa senang dengan proses pembelajaran di sekolah, dan adanya peran aktif dari orangtua untuk ikut menerapkan pendidikan ramah anak. Temuan penelitian ini merekomendasikan tentang dukungan berbagai pihak dalam kesuksesan implementasi program sekolah ramah anak dalam konteks sekolah dasar.

\section{UCAPAN TERIMA KASIH}

Penulis mengucapkan terimakasih kepada Prodi S2 Manajemen Pendidikan Universitas Ahmad Dahlan yang telah membantu terselesaikannya penelitian ini.

\section{DAFTAR PUSTAKA}

Afnibar, A. (2017). Child-Friendly School in Regional Perspective and the Role of Counseling Services. JBKI (Jurnal Bimbingan Konseling Indonesia), 2(2), 26. https://doi.org/10.26737/jbki.v2i2.252

Aguiar-Quintana, T., Araujo-Cabrera, Y., \& Park, S. (2020). The sequential relationships of hotel employees' perceived justice, commitment, and organizational citizenship behaviour in a high unemployment context. Tourism Management Perspectives, 35(December 2018).

https://doi.org/10.1016/j.tmp.2020.100676

Ang, M. C. H., Ramayah, T., \& Amin, H. (2015). Equality, Diversity and Inclusion: An International Journal Article information: An International Journal, Vol. 34(Iss 3), 186-200. https://doi.org/10.1108/GM-122013-0140

Bauer, T. N., Bodner, T., Erdogan, B., Truxillo, D. M., \& Tucker, J. S. (2007). Newcomer adjustment during organizational socialization: A meta-analytic review of antecedents, outcomes, and methods. Journal of Applied Psychology, 92(3), 707721. $\quad$ https://doi.org/10.1037/00219010.92.3.707

Cao, Y., Liu, J., Liu, K., Yang, M., \& Liu, Y. (2019). The mediating role of organizational commitment between calling and work engagement of nurses: A crosssectional study. International Journal of Nursing Sciences, 6(3), 309-314. https://doi.org/10.1016/j.jinss.2019.05.004

Collie, R. J., Shapka, J. D., \& Perry, N. E. (2011). Predicting teacher commitment: The impact of school climate and social-emotional learning. Psychology in the Schools, 48(10), 1034-1048.

Cornell, D., Gregory, A., Huang, F., \& Fan, X. (2013). Perceived prevalence of teasing and bullying predicts high school dropout rates. Journal of Educational Psychology, 105(1), 138-149. https://doi.org/10.1037/a0030416

Das, S. N. (2014). Do "child-friendly" practices affect learning? Evidence from Rural India. Department of Quantitative Social Science, Institute of Education, University of London.

Eliyana, A., Ma'arif, S., \& Muzakki. (2019). Job satisfaction and organizational commitment effect in the transformational leadership towards employee performance. European Research on Management and Business Economics, 25(3), 144-150. https://doi.org/10.1016/j.iedeen.2019.05.00 1

Godfrey, E. B., Osher, D., Williams, L. D., Wolf, S., Berg, J. K., Torrente, C., Spier, E., \& Aber, J. L. (2012). Cross-national 
measurement of school learning environments: Creating indicators for evaluating UNICEF's Child Friendly Schools Initiative. Children and Youth Services Review, 34(3), 546-557. https://doi.org/10.1016/j.childyouth.2011.1 0.015

Hall, G., \& Rodríguez, G. (2017). Habituation and conditioning: Salience change in associative learning. Journal of Experimental Psychology: Animal Learning and Cognition, 43(1), 48.

Hammig, B., \& Jozkowski, K. (2013). Academic Achievement, Violent Victimization, and Bullying Among U.S. High School Students. Journal of Interpersonal Violence, 28(7), 1424-1436. https://doi.org/10.1177/088626051246824 7

Hargreaves, A., \& O'Connor, M. T. (2018). Solidarity with solidity: The case for collaborative professionalism. Phi Delta Kappan, 100(1), 20-24. https://doi.org/10.1177/003172171879711 6

Imamoglu, S. Z., Ince, H., Turkcan, H., \& Atakay, B. (2019). The Effect of Organizational Justice and Organizational Commitment on Knowledge Sharing and Firm Performance. Procedia Computer Science, 158, 899-906. https://doi.org/10.1016/j.procs.2019.09.129

Itzkovich, Y., \& Heilbrunn, S. (2016). The Role of Co-Workers' Solidarity as an Antecedent of Incivility and Deviant Behavior in Organizations. Deviant Behavior, 37(8), 861-876.

https://doi.org/10.1080/01639625.2016.11 52865

Kegode, G., \& Kadenyi, A. M. (2016). Kenya's concept of child friendly school seen in light of julius nyerere's philosophy of education. International Journal of Innovative Research and Development, 5(9), 378-385.

Koster, F., \& de Beer, P. (2009). Sticking together or falling apart?: Solidarity in an era of individualization and globalization. Amsterdam University Press.

Kowtha, N. R. (2018). Organizational socialization of newcomers: the role of professional socialization. International Journal of Training and Development, 22(2), 87-106. https://doi.org/10.1111/ijtd.12120

Lian, B., Kristiawan, M., \& Fitriya, R. (2018). Giving creativity room to students through the friendly school's program. International Journal of Scientific and Technology Research, 7(7), 1-7. https://doi.org/10.31219/osf.io/zebpd

Marcone, R., Caputo, A., \& della Monica, C. (2015). Friendship competence in kindergarten and primary school children. European Journal of Developmental Psychology, 12(4), 412-428. https://doi.org/10.1080/17405629.2015.10 31215

Miles, M. B., Huberman, M. (1994). Qualitative Data Analysis: An Expended Sourcebook. Sage.

Rankin, C. H., Abrams, T., Barry, R. J., Bhatnagar, S., Clayton, D. F., Colombo, J., Coppola, G., Geyer, M. A., Glanzman, D. L., Marsland, S., McSweeney, F. K., Wilson, D. A., Wu, C. F., \& Thompson, R. F. (2009). Habituation revisited: An updated and revised description of the behavioral characteristics of habituation. Neurobiology of Learning and Memory, 92(2), $135-138$. https://doi.org/10.1016/j.nlm.2008.09.012

Raskauskas, J. L., Gregory, J., Harvey, S. T., Rifshana, F., \& Evans, I. M. (2010).

Bullying among primary school children in New Zealand: Relationships with prosocial behaviour and classroom climate. Educational Research, 52(1), 1-13. https://doi.org/10.1080/001318810035880 97

Scales, A. N., \& Quincy Brown, H. (2020). The effects of organizational commitment and harmonious passion on voluntary turnover among social workers: A mixed methods study. Children and Youth Services Review, 110 (January),

104782. https://doi.org/10.1016/j.childyouth.2020.1 04782

Schleifer, D., \& Rinehart, C. (2020). Teacher collaboration in perspective. A guide to research. Hungarian Educational Research Journal, 10(1), 95-96. https://doi.org/10.1556/063.2020.00008

Schneider, S. K., O'donnell, L., Stueve, A., \& Coulter, R. W. S. (2012). Cyberbullying, school bullying, and psychological distress: A regional census of high school students. American Journal of Public Health, 102(1), 

Bantul

171-177.

https://doi.org/10.2105/AJPH.2011.300308

Sharma, M. (2015). Impact of Teacher Commitment on Teacher Freezing. International Journal of Research in Economics and Social Sciences, 5(5), 8-16. https://www.academia.edu/12788220/Impa ct_of_Teacher_Commitment_on_Teacher_ Freezing

Slavin, R. E. (1994). Student teams-achievement divisions. In S. Sharan (Ed.), Handbook of cooperative learning methods. Westport: Greenwood press.

Stiglbauer, B., Gnambs, T., Gamsjäger, M., \& Batinic, B. (2013). The upward spiral of adolescents' positive school experiences and happiness: Investigating reciprocal effects over time. Journal of School Psychology, 51(2), 231-242.

Surya, E., Putri, F. A., \& Mukhtar. (2017). Improving mathematical problem-solving ability and self-confidence of high school students through contextual learning model. Journal on Mathematics Education, 8(1), 85-94.

https://doi.org/10.22342/jme.8.1.3324.8594

Wright, C. A., Mannathoko, C., \& Pasic, M. (2009). Child friendly schools manual. UNICE.

Zhang, L.-N., Pan, X.-D., \& Bai, D.-Q. (2018). Government Planning to Improve Quality of Chinars Basic Education. 205(Iccese), 201-205. https://doi.org/10.2991/icmesd18.2018 .82

Zhou, S., Li, X., \& Gao, B. (2020). Family/friends support, work-family conflict, organizational commitment, and turnover intention in young preschool teachers in China: A serial mediation model. Children and Youth Services Review, 113(January), 104997. https://doi.org/10.1016/j.childyouth.2020.1 04997 